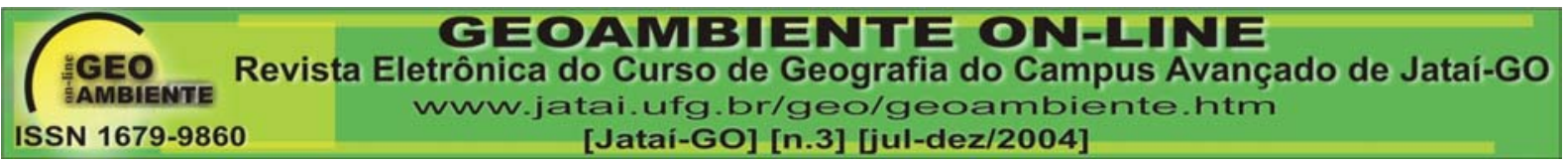

\title{
GESTÃO DE BACIAS HIDROGRÁFICAS: DESENVOLVIMENTO \\ INTEGRADO E POLÍTICAS PÚBLICAS PARA A BACIA \\ HIDROGRÁFICA DO RIO CORUMBATAÍ ${ }^{1}$
}

Shirley Cristina dos Santos ${ }^{1}$. Gilberto José Garcia ${ }^{2}$

(1 - Doutoranda em Geociências e Meio Ambiente. Universidade Estadual Paulista (UNESP). Campus de Rio Claro/SP - scsantos@rc.unesp.br. 2 - Prof. Dr. Voluntário da UNESP/CEAPLA - gilberto@,rc.unesp.br. )

\section{Resumo}

O tema desenvolvimento regional é uma inquietação que está, juntamente com as questões ambientais, presentes ao longo de todo o trabalho. A preocupação maior é entender as razões do atraso econômico da região da Bacia Hidrográfica do Corumbataí em relação a outras regiões e buscar alternativas sócio-econômicas para o benefício da comunidade local. As reflexões sobre o processo de desenvolvimento regional, o entendimento das questões regionais, mais profundamente, do desenvolvimento e do emprego são elementos que colaboram para apreender a organização espacial da Bacia Hidrográfica do Rio Corumbataí.

Palavras Chave: Desenvolvimento Sustentável - Bacia Hidrográfica - Rio Corumbataí

\begin{abstract}
The subject regional development is a fidget that is, together with the ambient questions, gifts throughout all the work. The biggest concern is to understand the reasons of the economic delay at the region of Corumbataí River Watershed in relation to other regions and to search partner-economic alternatives for the local community benefit. The reflections on the process of regional development, the regional questions understanding like the development and the job, more deeply, are elements that contribute to apprehend the space organization of Corumbataí River Watershed.
\end{abstract}

Key words: Sustainable Development - Watershed -Corumbataí River.

\section{Introdução}

\footnotetext{
${ }^{1}$ Artigo referente à Tese de Doutorado em andamento cujo título é "Proposta de Desenvolvimento Integrado e Políticas Públicas para a Bacia Hidrográfica do Rio Corumbataí - SP".
} 


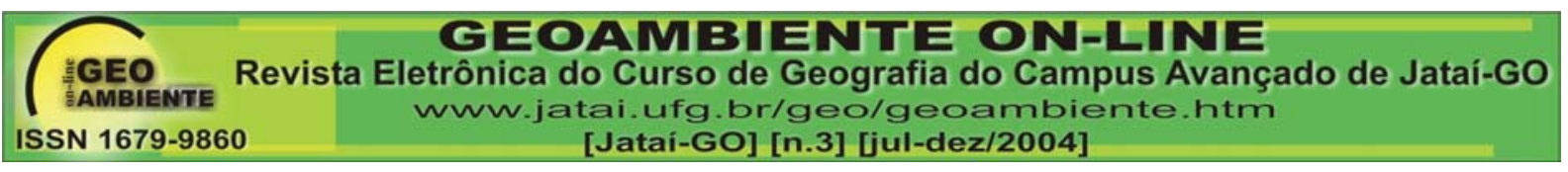

A compreensão da realidade regional envolve pelo menos três aspectos que devem ser considerados para o equacionamento do problema: a evolução histórica da ocupação do espaço regional, as características atuais desse espaço e a dinâmica econômica que prevalece na região nos períodos mais recentes, estabelecendo uma visão sobre as variáveis e condicionantes da dinâmica regional.

Compreender a situação desta região inserida no espaço que é composto por sete municípios paulistas, integrantes de uma das frentes mais avançadas do capitalismo brasileiro se constitui num dos cernes deste estudo, juntamente com a definição de diretrizes visando o planejamento e gestão ambiental da bacia hidrográfica em questão.

O uso dos instrumentos de gestão ambiental depende do desempenho das organizações que atuam no processo, desempenho esse que decorre da forma como estão estruturadas. $\mathrm{O}$ diagnóstico dessas organizações sugere a necessidade de reestruturações, para o que se devem encontrar alternativas mais apropriadas a cada situação.

\section{A área de estudo}

A Bacia Hidrográfica do Rio Corumbataí, localizada na porção centro-leste do Estado de São Paulo, possuindo a maior parte de suas terras na Depressão Periférica Paulista, abrange os municípios de Analândia, Corumbataí, Ipeúna, Itirapina, Santa Gertrudes, que compõem parte da região administrativa de Rio Claro, além de Charqueada e Piracicaba.

A Bacia Hidrográfica do Rio Corumbataí localiza-se entre os paralelos $22^{\circ} 04^{\prime} 46^{\prime \prime}$ e $22^{\circ} 41^{\prime} 28^{\prime \prime} \mathrm{S}$ e entre os meridianos $47^{\circ} 26^{\prime} 23^{\prime}$ " e $47^{\circ} 56^{\prime} 15^{\prime \prime} \mathrm{N}$. De acordo com KOFFLER (1993), sua altitude varia de 470m, na foz do Rio Corumbataí, a 1058m, na Serra do Cuscuzeiro, em Analândia (SP). A bacia ocupa uma área de 170.775,6 ha. Figura 1.

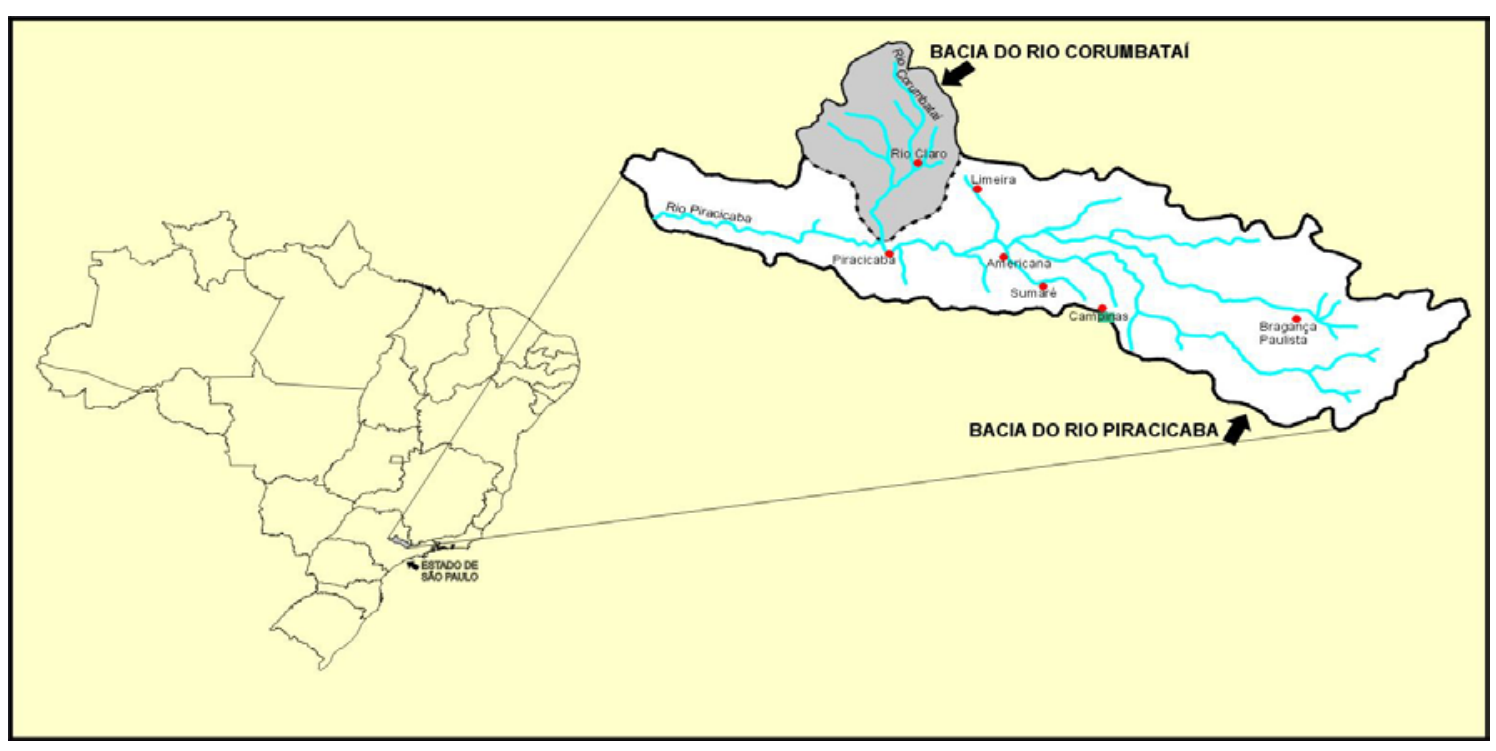

Figura 1-Localização da Bacia Hidrográfica do Rio Corumbataí/SP. 


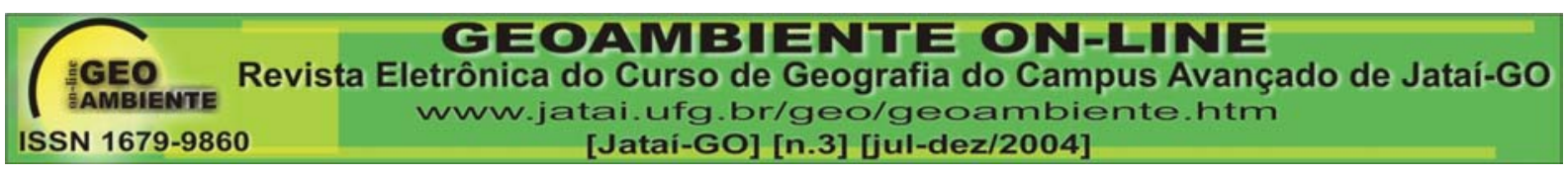

A Bacia Hidrográfica do Rio Corumbataí conta com uma população total de aproximadamente 218.000 habitantes. Sendo que deste total grande parte da população reside nas áreas urbanas, em casos como no município de Rio Claro e Santa Gertrudes este índice pode chegar a 97\%. O único caso existente na bacia de população rural maior que população urbana ocorre no município de Corumbataí, onde a população rural equivale a $60 \%$ da população total. Quando se calcula o total da população residente na área da bacia, verifica-se que a mesma é predominantemente urbana, com aproximadamente 95\% dos indivíduos vivendo nas cidades. A partir da Tabela 1 pode-se verificar a distribuição da população, nas áreas rurais e urbanas, nos municípios compreendidos pela Bacia Hidrográfica.

Tabela 1 -População residente nos Municípios da Bacia Hidrográfica do Rio Corumbataí (IBGE, 2003).

\begin{tabular}{l|c|c|c}
\hline \multicolumn{1}{c|}{ Município } & População urbana & População rural & População total \\
\hline Analândia & 2.646 & 930 & 3.576 \\
\hline Charqueada & 11.698 & 1.316 & 13.014 \\
\hline Corumbataí & 1.715 & 2.073 & 3.788 \\
\hline Ipeúna & 3.431 & 890 & 4.321 \\
\hline Itirapina & 11.151 & 1.654 & 12.805 \\
\hline Rio Claro & 159.431 & 4.867 & 164.414 \\
\hline Santa Gertrudes & 15.468 & 377 & 15.845 \\
\hline Total & $\mathbf{2 0 5 . 5 4 0}$ & $\mathbf{1 2 . 1 0 7}$ & $\mathbf{2 1 7 . 7 6 3}$ \\
\hline
\end{tabular}

Na região há a predominância da atividade agrícola temporária com a cana-de-açúcar, que está presente em todos os municípios e ocupa a maioria da área plantada dentre todas as atividades agrícolas. A cana-de-açúcar é hoje uma das maiores fontes de renda da região. $\mathrm{O}$ milho e o arroz também estão presentes na bacia, mas com um número de hectares menos representativo, mas está presente principalmente nas pequenas propriedades. $\mathrm{O}$ café e a laranja são os principais representantes das culturas permanentes. Na Tabela 2 pode-se verificar as principais atividades agrícolas encontras na Bacia Hidrográfica, de acordo com cada município. 
Tabela 2- Área (ha) das principais culturas nos Municípios da Bacia Hidrográfica do Rio Corumbatai (2003).

\begin{tabular}{c|c|c|c|c|c|c|c}
\hline Município & Analândia & Charqueada & Corumbataí & Ipeúna & Itirapina & $\begin{array}{l}\text { Rio } \\
\text { Claro }\end{array}$ & $\begin{array}{l}\text { Santa } \\
\text { Gertrudes }\end{array}$ \\
\hline algodão & 0 & 0 & 8 & 0 & 0 & 40 & 0 \\
\hline alho & 0 & 0 & 2 & 0 & 0 & 0 & 0 \\
\hline arroz & 60 & 20 & 45 & 90 & 30 & 180 & 16 \\
\hline café & 112 & 6 & 100 & 11 & 39 & 73 & 8 \\
\hline $\begin{array}{c}\text { cana-de- } \\
\text { açúcar }\end{array}$ & 1.900 & 9.500 & 1.715 & 4.868 & 3.666 & 9.746 & 4.815 \\
\hline feijão & 80 & 0 & 11 & 13 & 32 & 37 & 0 \\
\hline laranja & 2.059 & 6 & 1.654 & 85 & 1.965 & 1.742 & 152 \\
\hline mandioca & 0 & 0 & 5 & 13 & 93 & 125 & 23 \\
\hline milho & 600 & 100 & 650 & 240 & 490 & 1.150 & 360 \\
\hline
\end{tabular}

Na pecuária o que predomina em todos os municípios é o rebanho bovino seguido do rebanho de suínos e eqüinos. Uma atividade pecuária crescente e importante na bacia é a criação e abate de aves. Há em todos os municípios a presença de criadores e um número expressivo de cabeças em Rio Claro e Itirapina. A partir da Tabela 3 pode-se visualizar as principais atividades pecuárias na Bacia Hidrográfica.

Tabela 3- Criação de animais nos Municípios da Bacia Hidrográfica do Rio Corumbataí (2003).

\begin{tabular}{c|c|c|c|c|c|c|c}
\hline Município & Analândia & Charqueada & Corumbataí & Ipeúna & Itirapina & Rio Claro & $\begin{array}{c}\text { Santa } \\
\text { Gertrudes }\end{array}$ \\
\hline bovinos & 12.500 & 3.916 & 15.450 & 7.350 & 16.453 & 12.980 & 495 \\
\hline suínos & 800 & 694 & 910 & 8.550 & 3.728 & 2.450 & 245 \\
\hline eqüinos & 750 & 250 & 765 & 480 & 743 & 953 & 93 \\
\hline bufalinos & 380 & 0 & 39 & 50 & 138 & 107 & 0 \\
\hline asininos & 160 & 0 & 7 & 3 & 2 & 6 & 2 \\
\hline muares & 0 & 100 & 180 & 90 & 81 & 109 & 15 \\
\hline caprinos & 0 & 42 & 271 & 31 & 54 & 135 & 23 \\
\hline ovinos & 0 & 232 & 103 & 255 & 310 & 373 & 103 \\
\hline aves & 63.900 & 102.691 & 194.507 & 161.340 & 1.871 .130 & 1.187 .868 & 905 \\
\hline
\end{tabular}

A Bacia Hidrográfica do Rio Corumbataí apresenta um potencial elevado para as atividades turísticas, principalmente relacionadas à natureza. Todos os municípios apresentam uma variedade de atrativos naturais e culturais que podem ser utilizados para o lazer da população local e de outras regiões. O município de Analândia é regionalmente conhecido 


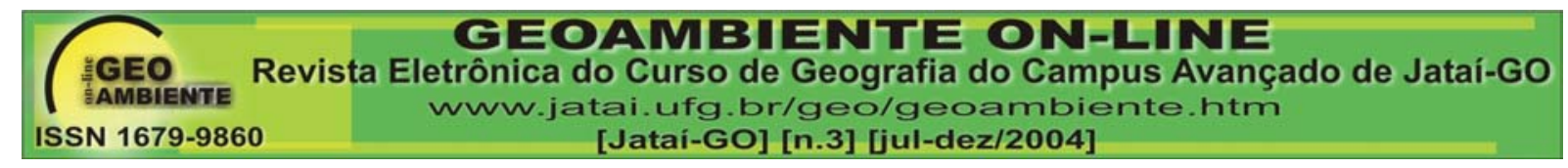

pelos seus morros e cachoeiras. Itirapina e Ipeúna têm em seu território um grande número de cachoeiras e grutas que são exploradas principalmente com o turismo de aventura e o ecoturismo. Em Corumbataí e Rio Claro há a presença do turismo cultural com festas e exposições. Os demais municípios da bacia utilizam os atrativos regionais.

\section{O papel do poder público no desenvolvimento econômico local e regional}

O desenvolvimento econômico brasileiro tem sido marcado, nas últimas décadas, pelo ritmo acelerado de concentração populacional e de atividades nos grandes centros urbanos, conduzindo a situações inconvenientes. (ABLAS, 1995).

Neste momento, o setor público deve agir, por meio de suas ações indicativas e disciplinadoras, almejando a consecução de um crescimento regional mais harmônico, com vistas à melhoria da qualidade de vida da população, tanto das áreas congestionadas quanto às zonas mais periféricas.

Os tradicionais mecanismos de ação efetivados pelo poder público, nos últimos tempos, não têm sido suficientemente capazes de reduzir, aos níveis desejáveis, os desequilíbrios regionais existentes. Um dos elementos propulsores desse processo concentrador é a indústria, em grande medida responsável pelo ritmo de crescimento econômico do país e, em grande parte, pelas disparidades regionais.

Considerando que o desenvolvimento econômico de uma região deve se basear fundamentalmente na utilização racional e eficiente dos fatores de produção disponíveis (terra, capital, postos de trabalho e tecnologia), ainda, é preciso atentar para a promoção de seu desenvolvimento analisando as oportunidades de alocação e realocação de recursos para obtenção de maiores retornos (BORBA, 2001).

A compreensão do funcionamento de uma economia regional e da sua dinâmica pressupõe, inicialmente, a necessidade de apreender suas características, tanto no que diz respeito às atividades e seu inter-relacionamento como à organização territorial.

Ao definirmos o espaço local como um marco estratégico na orientação de processos de desenvolvimento, precisamos buscar referências que indiquem os passos dados na direção da efetividade das políticas dali implementadas, sempre à luz do enfoque inovador orientado pela perspectiva da sustentabilidade (NOGUEIRA, 1999).

Essas referências devem ser identificadas na prática dos atores sociais, governamentais e de mercado. Em grande parte, dizem respeito à interferência das forças sociais e dos agentes governamentais locais, assim como dos agentes produtivos, sobre os fluxos de bens, serviços e informações que perpassam seu universo sócio-temporal. Interferir nas redes e cadeias que 


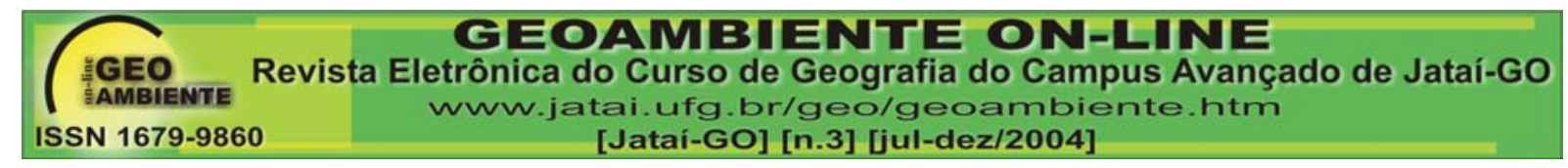

ordenam o modo de produção e o padrão de desenvolvimento se torna fator ainda mais decisivo num contexto que articula o ajuste e reestruturação econômica, empresarial e produtiva; a revolução tecnológica e os condicionamentos globais.

As possibilidades de atuação de cada governo são condicionadas pela estrutura social e pela organização econômica local, existindo uma diferenciação muito grande de cidade para cidade, em função do porte e da complexidade das relações sociais, não só no sentido econômico, mas de representação, participação e decisão. Qualquer política de geração de emprego e renda precisa estar fundamentada na formulação de um projeto de desenvolvimento baseado na realidade local e, em função dela, estabelecer as áreas de trabalho prioritárias.

O governo local, mais do que um agente realizador do desenvolvimento, deve funcionar como articulador e facilitador das ações de desenvolvimento. Estas ações não podem ocorrer como monopólio do poder público. Pelo contrário, sua eficácia será maior justamente quando o poder público for apenas um dos múltiplos agentes envolvidos no projeto de desenvolvimento local incorporado pela sociedade (AIYAR, 1996).

Desta forma, desenvolver uma região requer utilizar os fatores endógenos ao território, sem abrir mão dos fatores externos. Promover o desenvolvimento regional, finalmente, não significa somente privilegiar grandes empreendimentos industriais, mas sim em incentivar todos os projetos que façam uso do potencial de desenvolvimento e realizem o ajuste progressivo do sistema econômico local a fim de dotar os sistemas produtivos locais dos serviços necessários para resolver seus problemas de competitividade.

\section{Projetos e Políticas Públicas nas esferas federal e estadual brasileira}

Os percursos e as fontes que chegam à temática do desenvolvimento são diversos e combinados, tais como as ações cidadãs e os projetos demonstrativos focalizados, as iniciativas de fomento ao empreendedorismo, os movimentos ambientais e sócio-ambientais, as inovações nos parâmetros de gestão municipal e as tentativas de articulação de macroprogramas governamentais.

Há múltiplas iniciativas que sugerem o desenvolvimento como um processo nucleado a partir de experiências desencadeadoras. Nestes casos, a idéia do desenvolvimento regional aparece como extensão e desdobramentos de acúmulos focalizados, como uma perspectiva que traduz em arranjos progressivos no território, tais como novos atores, novas esferas de intervenção e novas ações, em vez de arranjos pré-desenhados.

O campo de fomento ao desenvolvimento regional, na sua expressão institucional hoje 


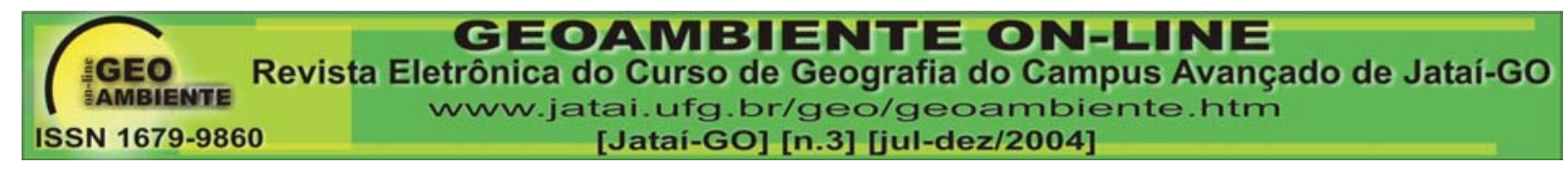

no Brasil, é predominantemente um complexo de fundamentos e métodos voltados para o desencadeamento de processos: as metodologias se definem como de indução ou apoio. $\mathrm{Na}$ própria intencionalidade que as caracteriza, sua implementação não é em si o desenvolvimento, mas um fator impulsionador, um fator visto como necessário. Outros fatores decisivos seriam por certo os elementos endógenos, as forças passíveis de emergir, ao gerar novos vínculos e caminhos, desde as bases locais (ALMEIDA, 1996).

A própria visibilidade dos processos intencionais e institucionais remetem a necessidade de levantar elementos mais de fundo, tomando como ponto de partida a discussão em torno do caráter estratégico ou não do desenvolvimento regional.

Neste sentido, o território, com seus recursos e arranjos institucionais, torna-se a base para a constituição do espaço produtivo e , como um efeito de reforço, faz com que a cooperação se converta em força produtiva, aproveitando a dinâmica das novas interações. $\mathrm{O}$ compartilhamento de saberes e a aprendizagem continuada, o uso socializado de meios técnicos e informacionais, o apoio às formas combinadas de competição e cooperação são fatores que criam as bases para novas solidariedades e para uma nova ética empresarial (AIYAR, 1996).

Desta forma, pode-se considerar a mudança no padrão de planejamento público como um sinal básico da mudança subjetiva dos atores e da forma institucional de regular as ações estratégicas. $\mathrm{O}$ ambiente inovador se relaciona com uma institucionalidade modificada pela esfera pública não-estatal, que estabelece desde baixo o nexo com os agentes e agências governamentais. Destaca-se, como elemento-chave, a identificação de práticas e instrumentos de gestão integrada de políticas públicas, a partir de espaços institucionais inovadores.

Ao contrário de políticas verticais emanadas do poder central, generalísticas para qualquer espaço geográfico e oriundas de estruturas administrativas nacionais de corte setorial, o desenvolvimento regional permite integrar programas públicos como foco na realidade local, de modo a rearticulá-los e recria-los a partir de iniciativas provenientes de novos arranjos institucionais, a exemplo de fóruns, comitês, consórcios e conselhos de desenvolvimento, que se construam com autonomia e legitimidade.

O desenvolvimento, neste sentido, exige, pois uma nova forma de gestão pública onde não apenas o poder governamental local, mas diferentes atores desempenham o papel de promotores e articuladores de políticas públicas, desde o desenho, até a implementação e acompanhamento das ações.

Neste contexto, verifica-se as articulações governamentais que contribuem através de seus projetos para o desenvolvimento econômico. No âmbito deste artigo serão descritos os 


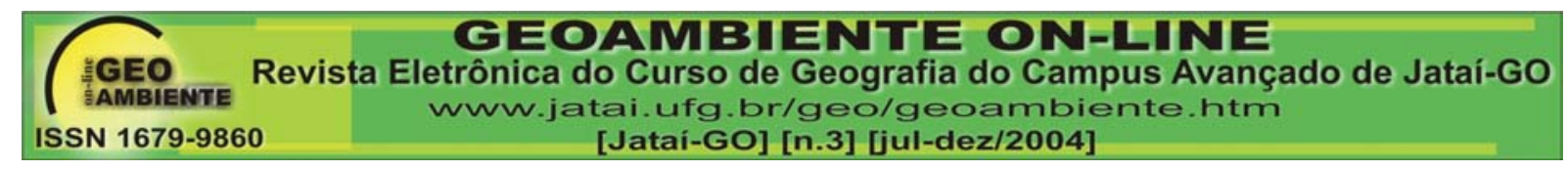

projetos de autoria do SEBRAE (Serviço Brasileiro de Apoio às Micros e Pequenas Empresas) e BNDES (Banco Nacional de Desenvolvimento Econômico e Social) e das possibilidades de projetos de incubadoras de empresas, além das relações intermunicipais existentes.

Desde meados de 2000 o SEBRAE Nacional e todas as suas unidades estaduais criaram o Programa SEBRAE de Desenvolvimento Local em substituição ao PRODER (Programa de Emprego e Renda). Tal mudança não foi apenas nominal, mas partiu da constatação de que a geração de emprego e renda está cada vez mais atrelada a processos de maior amplitude que implicam no estabelecimento de parcerias formais ou informais com o poder público, a sociedade civil e a própria comunidade, que para ser diretamente atingida precisa ser envolvida.

Além de outras iniciativas, como a capacitação de gestores em projetos de desenvolvimento sócio-econômico, realizadas em 2001, e que tem seu ponto de partida nos diagnósticos produzidos, iniciou-se a expansão em mais 44 municípios integrantes do Programa Comunidade Ativa com base na metodologia do DLIS (Desenvolvimento Local Integrado e Sustentável). Por intermédio destas ações o SEBRAE tem o intuito de contribuir com as comunidades locais na busca de alternativas para a construção da nova agenda do desenvolvimento.

O SEBRAE apresenta ainda outros projetos que contribuem para o desenvolvimento regional, principalmente ligados ao Turismo, Agronegócios e Cooperativas.

Na parte do Turismo encontra-se o PDTR (Programa de Desenvolvimento do Turismo Receptivo). Elaborado pelo Núcleo de Turismo do SEBRAE-SP, o PDTR aposta que de acordo com a diversidade de recursos naturais e culturais oferecidos, o PDTR desenvolverá junto com os parceiros locais, um Programa de Desenvolvimento personalizado, visando sempre que haja a complementaridade entre os produtos e serviços oferecidos pelo município ou região, facilitando a inserção no mercado e a manutenção da atratividade perante os turistas.

Com o setor de Agronegócios, o SEBRAE montou diversos programas, tais como: Sistema Agroindustrial Integrado, Capacitação Rural e Qualidade Total Rural.

O SAI (Sistema Agroindustrial Integrado) é um programa do SEBRAE-SP em parceria com a Secretaria do Estado da Agricultura e Abastecimento, que já funciona em 363 municípios do Estado de São Paulo beneficiando 92 mil clientes, entre produtores, empresários e empreendedores rurais. Seu objetivo principal é transformar o pequeno agricultor e pecuarista em empresário rural, melhorando as condições de vida no campo, 


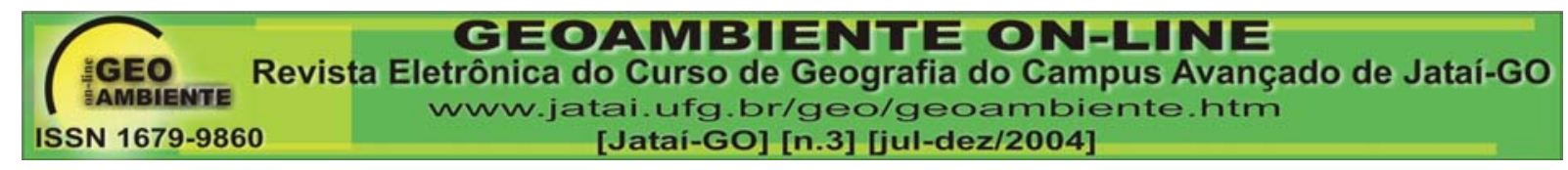

aumentando a renda familiar e gerando empregos.

O objetivo do programa Capacitação Rural é capacitar o produtor rural, fazendo com que ele administre sua propriedade como uma empresa. Em virtude do aumento da competitividade, há a necessidade de baixar custos, otimizar recursos e vender de forma diferenciada. Através do Projeto de Capacitação Rural, o empresário rural conhece novos processos e ferramentas para facilitar o gerenciamento da empresa rural.

O programa Qualidade Total Rural foi desenvolvido para melhorar a qualidade e a renda da empresa rural, aumentando a produtividade, reduzindo custos, melhorando o ambiente de trabalho e enfatizando as atividades de maior valor agregado ou de maior retorno de capital aplicado. Durante oito meses, os produtores rurais desenvolvem procedimentos e técnicas visando à implantação da QT (Qualidade Total) em suas propriedades. Eles assimilam conceitos de qualidade, negócio agrícola, cliente, fornecedor, processo, produto, noções básicas de produtividade e a importância destes para a sua empresa.

No âmbito das cooperativas, o SEBRAE SP oferece serviços de apoio, através da Área de Ações Associativistas, que disponibiliza um programa destinado a orientar grupos em formação, como também fornecer subsídios para grupos já constituídos. Desse programa constam um ciclo de palestras de sensibilização dirigida a grupos em formação, reuniões de trabalho com dirigentes de cooperativas e entidades ligadas ao cooperativismo, consultoria especializada nas áreas administrativa e jurídica dirigida a grupos já constituídos. Este trabalho é realizado em parceria com a OCESP (Organização das Cooperativas do Estado de São Paulo), SESCOOP (Serviço Nacional de Aprendizagem do Cooperativismo), ICA (Instituto de Cooperativismo e Associativismo) da Secretaria de Agricultura e Abastecimento do Estado de São Paulo e a Secretaria de Emprego e Relações do Trabalho do Estado de São Paulo.

O BNDES apresenta uma política de recursos e fomento com diversas modalidades que podem contribuir para o desenvolvimento regional, entre eles está o Programa de Desenvolvimento Local.

O Programa de Desenvolvimento Local - DL tem o objetivo de contribuir para a promoção do desenvolvimento de determinados espaços geográficos, definidos pelas suas relações de integração e articulação cultural, econômica e ambiental, e que são caracterizados por terem expressivos contingentes de população de baixa renda e apresentarem disparidades sociais. Em resumo, seu objetivo é formular e executar ações que, levando em conta as vocações locais, permitam a construção de processos de desenvolvimento cujos resultados beneficiem a maioria da população. 


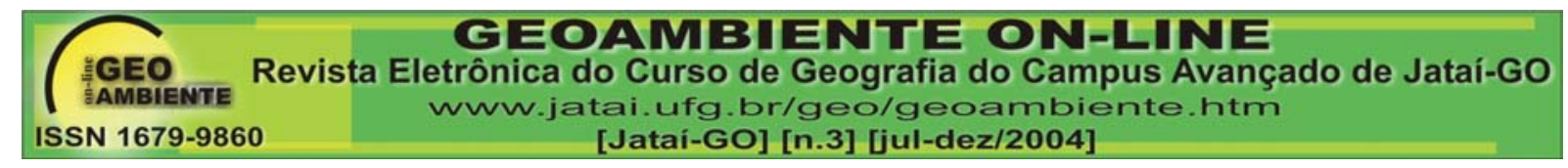

O foco inicial e fundamental da ação é a população de baixa renda, e se busca, ao longo do processo, promover sua inclusão social, através de ações de mobilização, organização, capacitação técnica e da execução de projetos de natureza social e econômica que daí possam decorrer.

Outro projeto do BNDES é o PRONAF (Programa Nacional de Fortalecimento da Agricultura Familiar) que tem por objetivo financiar as atividades agropecuárias e nãoagropecuárias exploradas mediante emprego direto da força de trabalho do produtor rural e sua família.

O MODERFROTA (Projeto de Modernização da Frota de Tratores Agrícolas e Implementos Associados e Colheitadeiras) tem como objetivo financiar a aquisição de tratores agrícolas e implementos associados, colheitadeiras e equipamentos para preparo, secagem e beneficiamento de café.

O PROIRRIGA (Programa de Apoio à Agricultura Irrigada) tem por objetivo apoiar o desenvolvimento da agricultura irrigada, de maneira a assegurar maior estabilidade à produção, sobretudo de olerícolas, grãos e frutas.

O PROPFLORA (Programa de Plantio Comercial de Florestas) tem como objetivo contribuir para a redução do déficit existente no plantio de árvores utilizadas como matérias primas pelas indústrias, principalmente a moveleira; incrementar a diversificação das atividades produtivas no meio rural; gerar emprego e renda de forma descentralizada; alavancar o desenvolvimento tecnológico e comercial do setor, assim como a arrecadação tributária; fixar o homem no meio rural e reduzir sua migração para as cidades, por meio da viabilização econômica de pequenas e médias propriedades; e contribuir para a preservação das florestas nativas e ecossistemas remanescentes.

O PRODECOOP (Programa de Desenvolvimento Cooperativo para Agregação de Valor à Produção Agropecuária) tem por objetivo incrementar a competitividade do complexo agroindustrial das cooperativas brasileiras, por meio da modernização dos sistemas produtivos e de comercialização.

O Programa Especial de Financiamento Agrícola pode ser utilizado para financiar a aquisição de máquinas, tratores, colheitadeiras, equipamentos e implementos agrícolas inclusive plantadeiras destinadas a plantio sob a técnica de "plantio direto"; sistemas de irrigação; ordenhadeiras mecânicas, tanques de resfriamento e homogeneização de leite; máquinas e equipamentos para avicultura, unidades de beneficiamento de sementes; implantação ou modernização de frigoríficos com atuação em âmbito municipal ou estadual; beneficiamento e conservação de pescados oriundos da aqüicultura. Além de financiar a 


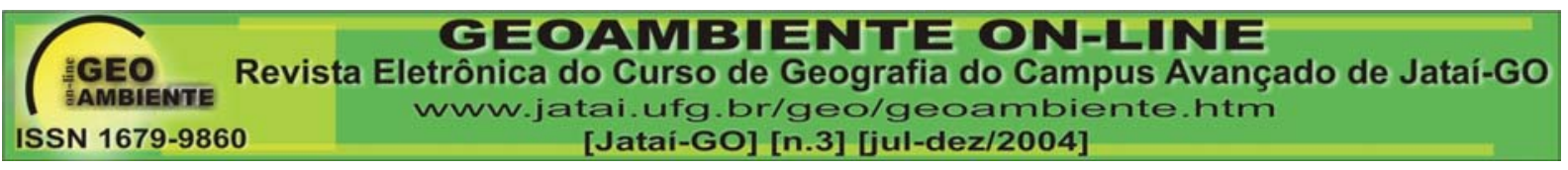

manutenção e recuperação de máquinas.

A incubadora de empresa é um espaço físico destinado a atender, por tempo limitado, pessoas ou grupos que queiram criar micro ou pequenas empresas de base tecnológica e/ou tradicional, mas que não possuem capital para investir no projeto. Além do espaço físico, a incubadora fornece ainda suporte técnico, consultoria para o desenvolvimento da nova atividade e um serviço de marketing e divulgação.

É um ambiente que favorece a criação e o desenvolvimento de empresas e produtos, em especial os inovadores e intensivos em conhecimento. Esse ambiente oferece às empresas emergentes, por custos inferiores aos de mercado, elementos como área física e infraestrutura, vizinhos comprometidos com a inovação, serviços de apoio e serviços de promoção de sinergia intramuros e extramuros.

Para a região da Bacia do Rio Corumbataí existe a primeira incubadora de empresas, constituída com o apoio da UNESP, a INCUNESP-RC.

A INCUNESP-RC (Incubadora de Empresas de Base Tecnológica da Unesp) surge em 2003 com o apoio do Sebrae e da Prefeitura Municipal de Rio Claro, como a resposta da UNESP a esse novo paradigma do desenvolvimento econômico global: a moderna tendência de disponibilizar avanços da ciência, transformando-os em demandas empresariais de sucesso.

As incubadoras de base tecnológica operam com produtos inovadores de elevado valor agregado. A comunidade se envolve e partilha, solidariamente, talento e experiência. Entidades de apoio a empreendedores se dedicam profundamente ao sucesso dessas iniciativas. Outro fator de sucesso é a consolidação de cadeias produtivas: produtos que completam uma linha de produtos e não competem desastrosamente.

No âmbito das relações intermunicipais, os consórcios na forma de associações ou de pactos, instrumentalizam a união entre os municípios e têm o intuito de resolver problemas e implementar ações de interesse comum, por meio da articulação e racionalização dos recursos de cada esfera de poder. São instrumentos que tem viabilizado o planejamento local e regional, auxiliando na organização de planos, avaliações e controles; a superação de problemas locais; possibilitando ganhos de escala de produção; a racionalização no uso de recursos financeiros, humanos, tecnológicos e ambientais; a modernização administrativa, por meio da padronização de suprimentos e procedimentos administrativos; o aumento da capacidade de cooperação técnica; e a implantação e regulação de políticas públicas regionalizadas.

Têm sido utilizados por muitas administrações como um captador de recursos já que muitos governos estatais e ministérios, ao longo dos anos, vêm estimulando a formação de 


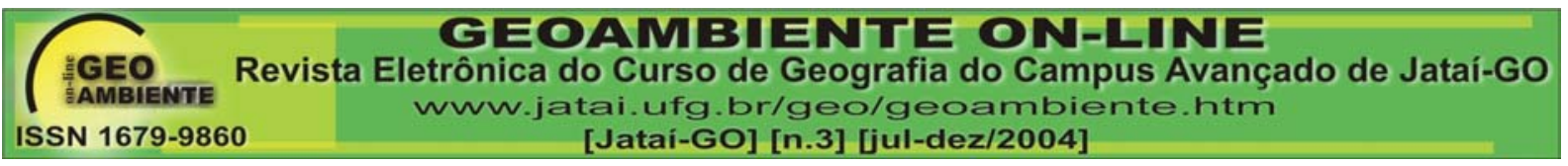

consórcios, bem como priorizando o atendimento às demandas regionais.

Os consórcios são uma forma de organizar a regionalização de forma ascendente, isto é, formado a partir dos municípios, de suas características locais e suas dificuldades, para discutir as ações regionais, sem que os municípios percam a sua autonomia. Esse instrumento não se configura como esfera descentralizada do Estado. Caracteriza-se como um arranjo institucional que pode possibilitar a descentralização das políticas estaduais e nacionais, e enseja a parceria entre o setor público e privado.

Há também outras formas de parcerias intermunicipais, como associações, as agências, os fóruns, as autarquias, as redes e as câmaras intermunicipais, os comitês, que também têm auxiliado aos municípios na solução de problemas comuns que transcendem a esfera de um único município.

Ressalta-se que os municípios devem ter interesses comuns e finalidade de atuação coincidente. Os consórcios são, portanto, um compromisso de mútua cooperação entre os consorciados. Essa cooperação pode ter por escopo a realização de obras, serviços e atividades temporárias e permanentes, que, embora, localizadas em um município ou Estado, seja de interesse de outros ou de toda uma região.

Neste caso, o consórcio intermunicipal é resultado da união de vários municípios que constituíram uma sociedade civil sem fins lucrativos cujos fins e objetivos estão fixados no seu Estatuto Social.

Várias obras públicas têm sido feitas de forma consorciada. Esse é um tipo de consórcio no qual os objetivos e etapas são preestabelecidos, o que facilita a identificação das responsabilidades de cada membro consorciado. Canalização de rios, manutenção de estradas vicinais, aquisição ou locação de equipamentos para uso comum, são exemplos de ações que podem ser feitas conjuntamente.

$\mathrm{Na}$ área de recuperação e proteção ambiental, há muitas experiências de consórcio. A preservação de recursos hídricos; o tratamento e a destinação do lixo, ações de saneamento básico; a preservação da mata ciliar; entre outras ações, requerem ações articuladas. Não há como pensar na preservação de um rio, sem pensar em sua bacia hidrográfica e nos municípios abrangidos por ela.

A promoção do desenvolvimento sustentável da região pode ser pensada de forma cooperada. Um plano de desenvolvimento turístico regional pode ser uma alternativa para municípios que, isoladamente, não detêm grande potencial turístico, mas que em conjuntos, podem ser atrativos. $\mathrm{Na}$ área de desenvolvimento, podem ser feitas capacitações profissionais, bem como estudos de cadeias produtivas existentes na região e/ou apoio às micros, pequenas 


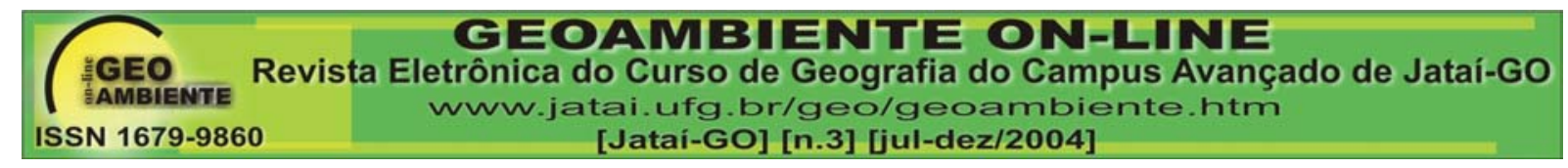

e médias empresas regionais.

As ações a serem realizadas conjuntamente com os municípios devem ser precedidas de um estudo de viabilidade econômica que verifique a oportunidade e a forma de execução da atividade e defina a participação de cada município.

Os municípios pertencentes a Bacia Hidrográfica do Rio Corumbataí participam do Consórcio Intermunicipal das Bacias dos rios Piracicaba, Capivari e Jundiaí. A finalidade da entidade é contribuir para a implantação e implementação de uma gestão descentralizada e participativa dos recursos hídricos e desenvolver, em parcerias com outras entidades públicas e privadas, projetos e ações práticas visando à recuperação e preservação dos rios da região, de forma a garantir o desenvolvimento econômico.

Os objetivos do Consórcio são apoiar, influenciar, contribuir, implantar e participar dos Sistemas Nacional e Estaduais Integrados de Gestão dos Recursos Hídricos, descentralizados e participativos; do Comitê, Agência de Bacia e da Cobrança pelo Uso da Água; nas legislações referentes aos recursos hídricos, defendendo os interesses e benefícios regionais e formas que garantam que os recursos arrecadados com a cobrança pelo uso da água permaneçam, ou retornem, à sua região de origem; e do planejamento regional integrado para o desenvolvimento sustentável.

\section{O Turismo no contexto das potencialidades de desenvolvimento regional.}

O turismo é uma grande industria que emprega mais pessoas do que qualquer outro ramo. Pesquisas revelam que um em cada dez trabalhadores do Brasil atua na área do turismo. O setor é responsável por cerca de 8,2\% das exportações mundiais e representa cerca de $10 \%$ do produto interno bruto.

Por tudo isso é que se percebe a importância das atividades turísticas no desenvolvimento econômico de municípios e de regiões que têm na natureza um aliado importante para o crescimento.

Com isso, também é possível perceber a tendência de que as atividades não-agrícolas cada vez mais se constituem em formas alternativas e/ou complementares de geração de renda no meio rural. Entre elas se destacam também atividades ligadas ao lazer e de turismo no meio rural (SCHNEIDER, 2003).

O turismo contemporâneo vem sendo marcado pela profusão de formas alternativas que são oferecidas em oposição ao chamado turismo convencional. As novas estruturas econômicas, o desenvolvimento da urbanização e os efeitos decorrentes desse fenômeno, bem como os valores captados do ambientalismo, entre muitos outros fatores, se alinham para 


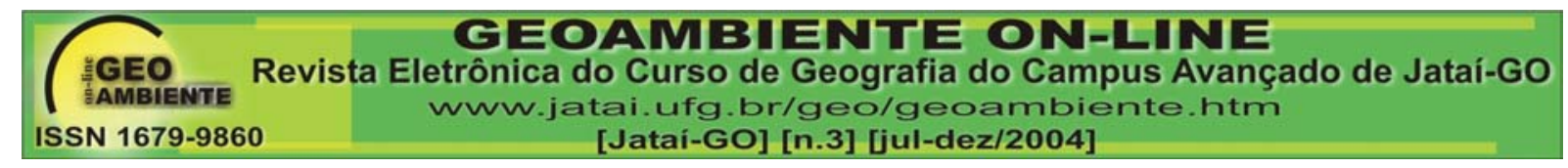

explicar a proliferação destas formas alternativas de praticar e entender o turismo (RODRIGUES, 1997).

Embora existentes há muito tempo, algumas modalidades ressurgem renovadas por iniciativas públicas e particulares e vêm garantindo a revitalização de áreas decadentes e estagnadas. É o caso do chamado Turismo Rural.

A ocorrência do Turismo Rural pressupõe áreas dotadas de recursos diferenciados do meio urbano, um mínimo de infra-estrutura representada pelas vias de acesso e meios de transportes, possibilidades de alojamento e alimentação e, sobretudo na proximidade de uma demanda, ou a possibilidade de captá-la.

O turismo no meio rural pode se constituir em um dos vetores do desenvolvimento local, desde que as decisões sejam tomadas no âmbito local, que haja controle dos processos de desenvolvimento por atores sociais locais, e que as comunidades locais se apropriem dos benefícios gerados. Constitui-se, então numa forma de valorização do território, pois ao mesmo tempo em que depende da gestão do espaço local e rural para o seu sucesso, contribui para a proteção do meio ambiente e para a conservação do patrimônio natural, histórico e cultural do meio rural. Torna-se, portanto um instrumento de estímulo à gestão e ao uso sustentável do espaço local, que devem beneficiar prioritariamente a população local direta e indiretamente envolvida com as atividades turísticas.

Através do turismo no meio rural a comunidade pode ser beneficiada, pois acaba compartilhando dos benefícios indiretos gerados, tais como: melhoria da infra-estrutura e de serviços públicos (saneamento básico, segurança, hospitais, transporte); aumento no número de indústrias e de estabelecimentos comercias com demanda por produtos para o consumo imediato, presentes, comidas típicas, "souvenir"; desenvolvimento da indústria do lazer; melhoria indireta do setor agrícola por meio da potencialização da demanda de produtos que qualidade típica de cada região (mel, queijos, embutidos); aumento de construções; recuperação do patrimônio histórico e cultural; recuperação de áreas degradadas e de florestas nativas (CAMPANHOLA, 2001).

Um dos pontos mais importantes a considerara na perspectiva do desenvolvimento local refere-se ao aproveitamento das especificidades de cada localidade ou território e ao pleno aproveitamento das suas potencialidades e oportunidades. Deve-se, assim, explorar o específico, os chamados nichos, diferentemente do que é preconizado no turismo massivo, que tende a homogeneizar os produtos e concentrar-se em determinados locais.

De acordo com GRAZIANO DA SILVA (1998) qualquer iniciativa regional ou local para o desenvolvimento do turismo no meio rural deve se iniciar por um zoneamento 


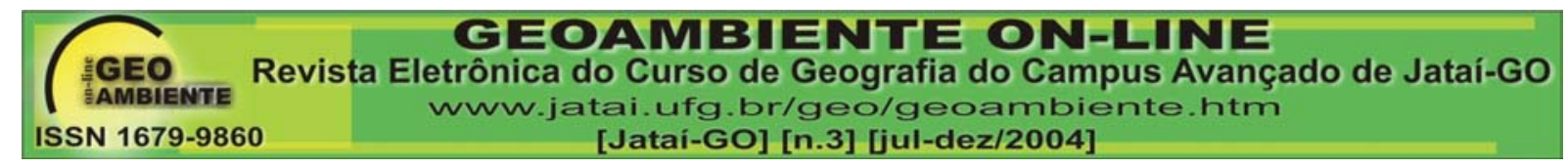

econômico e ecológico do espaço rural, que se refere à descrição e à caracterização dos recursos climáticos e ambientais e à espacialização dessas informações com os objetivos de facilitar o planejamento da ocupação organizada de um local e de se priorizar as atividades econômicas que prezem pelo maior retorno social e pela conservação do meio ambiente. Seguido de uma descrição dos principais produtos turísticos e análise de sua demanda atual e potencial, do ordenamento territorial das atividades produtivas, e do cadastramento de agricultores que seriam beneficiados devido ao seu potencial de explorar o agroturismo.

\section{Planejamento e Modelo de Gestão}

Há mais de uma década, o Brasil vive uma rica experiência de redesenho do seu sistema federativo. O sentido da mudança - pelo menos ao nível do discurso político - aponta para a descentralização, bem como para o fortalecimento da capacidade decisória das instâncias subnacionais de governo. Para os críticos do sistema anterior, a descentralização implicaria a transferência de competências e atribuições de outras esferas estatais para os municípios, com concomitante descentralização na gestão dos recursos, conferindo-lhes maior autonomia nas decisões e nos gastos públicos (ALMEIDA, 1996).

A descentralização tem se tornado a grande moda a partir do início dos anos 90. Alguns a vêem como uma importante ferramenta para o desenvolvimento rural e para a redução da pobreza, outros como um caminho para desmantelar economias centrais, e ainda alguns como forma de semear a democracia. (ALMEIDA, 1996).

Para AIYAR (1996), por exemplo, a descentralização pode trazer grandes benefícios, destacando-se: o aumento do retorno dos governos à sociedade; o aumento do fluxo de informações entre o governo e a sociedade; a promoção de maiores atividades de participação e de associativismo; o aumento da transparência; o aumento da credibilidade; a integração da sociedade com o Estado; o reforço e revigoramento da democracia ao nível nacional; a ampliação do escopo do projeto para além da agricultura; a redução das disparidades regionais; a solução dos problemas da complexidade e da coordenação; a atenção maior aos fatores sócio-culturais; a adaptação do desenvolvimento às condições locais; e o reforço do compromisso do governo central com o desenvolvimento rural. É óbvio que cada um desses benefícios não ocorre independentemente dos outros, havendo grandes discrepâncias em razão das próprias diferenças regionais e locais, mas no médio e longo prazo eles tendem a convergir na medida em que as grandes transformações sócio-políticas sejam processadas. 


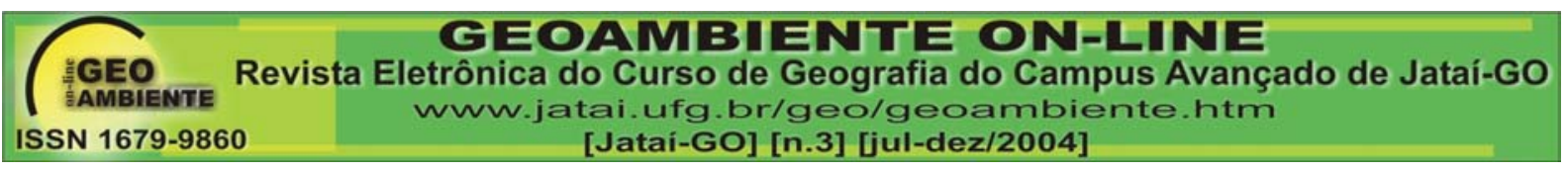

Está evidente que não há uma saída única para o desenvolvimento de uma região. Qualquer programa ou projeto de desenvolvimento deve respeitar as particularidades locais sociais, culturais, econômicas e ambientais-, de modo a não agravar as desigualdades. E o processo de descentralização, particularmente o da municipalização, tem importante papel nisso, pois é no nível local que as peculiaridades se expressam, que os atores sociais interagem, que as políticas públicas se viabilizam, enfim que as ações efetivamente se realizam. O processo de municipalização, se bem conduzido, pode atacar as profundas disparidades regionais e locais, contribuindo para a solução dos problemas e para a integração das políticas ao nível nacional.

De acordo com GARCIA (2004) a forma complexa que verificamos no meio ambiente indica de forma substancial o grau de dificuldade existente na elaboração e gestão de projetos de desenvolvimento econômico e ambiental.

$\mathrm{O}$ ordenamento territorial, um processo de planejamento para o desenvolvimento sustentado, envolve uma estratégia para melhorar e disciplinar as relações entre os aspectos ecológicos e sócio-econômicos dos sistemas ambientais. O sucesso desse ordenamento dependerá da participação de todos os setores da comunidade envolvida na dinâmica territorial (GARCIA, 2004).

Para SACHS (2000), verifica-se que a Gestão Ambiental é o processo de articulação das ações dos diferentes agentes sociais que interagem em um dado espaço, com o objetivo de garantir a adequação dos meios de exploração dos recursos ambientais, econômicos e sócioculturais, às características do meio ambiente.

Isso torna a Gestão Ambiental uma atividade voltada à formulação de princípios e diretrizes à estruturação de sistemas gerenciais e à tomada de decisões que tem como objetivo final à promoção de forma coordenada, o inventário, uso, controle, proteção e conservação do ambiente visando atingir o objetivo estratégico de Desenvolvimento Sustentado.

Para a proposição do modelo de Gestão do espaço são imprescindíveis métodos e estratégias que incluam e integrem ao desenvolvimento as variáveis ambientais, sociais, econômicas e de políticas públicas (SARACENO, 1998).

Entre os princípios observados estão: a participação da comunidade local no encaminhamento das decisões, a introdução de mecanismos públicos que possibilitem a igualdade de acesso aos benefícios gerados e o compromisso com a conservação dos recursos naturais e recreativos e da qualidade ambiental. 


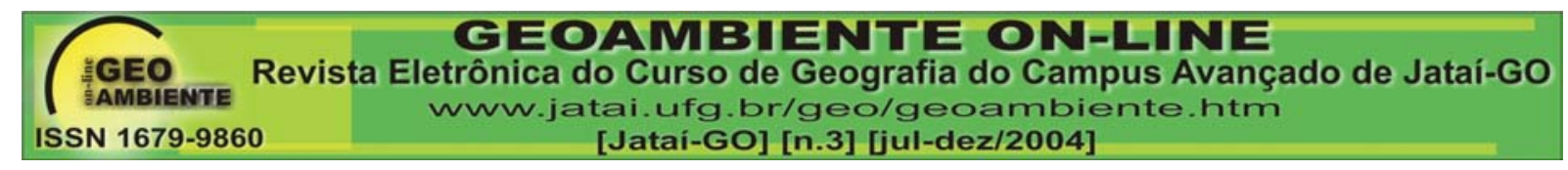

Para que isso aconteça, um modelo de gestão deve atender alguns requisitos visando alcançar os objetivos relacionados ao desenvolvimento regional. Tal modelo está baseado em CAMPANHOLA (2001) onde:

Faz-se necessário estimular a implementação de programas e projetos de desenvolvimento local que possibilitem a emergência de novos atores sociais e um reordenamento territorial com a criação de novos espaços rurais que não sejam necessariamente confinados aos limites geográficos dos atuais municípios, de modo a introduzir outras variáveis econômicas, sociais e ambientais que sejam mais coerentes com as oportunidades emergentes de atividades produtivas e de serviços.

O estabelecimento de mecanismos ou estruturas que promovam o processo participativo das diferentes representações dos atores sociais do meio rural - de segmentos agrícolas e não-agrícolas -, contribuem de modo a estimular a formação de consciência e o exercício democrático; deve haver o monitoramento e a avaliação periódica das ações programadas e implementadas, divulgando e discutindo os seus resultados com a comunidade, a fim de conferir transparência ao processo e de prezar pela sua continuidade mesmo diante das mudanças periódicas no poder executivo municipal;

O estímulo à organização dos produtores e trabalhadores rurais por meio de associações ou cooperativas, no sentido de legitimar a sua participação nas tomadas de decisão.

O oferecimento de novas alternativas com relação às atividades rurais não-agrícolas, sendo de forma sustentável e visando os novos modelos de utilização do espaço rural, como é o caso do turismo rural e do ecoturismo.

Em suma, o planejamento vai possibilitar o delineamento de políticas de desenvolvimento que dêem suporte a pluriatividade. Nesses casos, as diretrizes para as políticas públicas seriam no sentido de: a) identificar as potencialidades locais, incluindo as atividades não-agrícolas; b) organizar a participação das comunidades locais; c) solucionar os entraves de infra-estrutura que dificultam o aproveitamento das oportunidades; d) reestruturar os instrumentos institucionais para que favoreçam as ações intersetoriais e e) rever as formas de atuação das instituições de pesquisa e de extensão do setor público.

\section{Considerações Finais}

O desenvolvimento regional não se reduz apenas ao crescimento agrícola. Essa é uma afirmação que se tornou corriqueira na produção acadêmica e nas instituições governamentais e não governamentais de desenvolvimento no mundo todo. Por mais relevante que seja o 


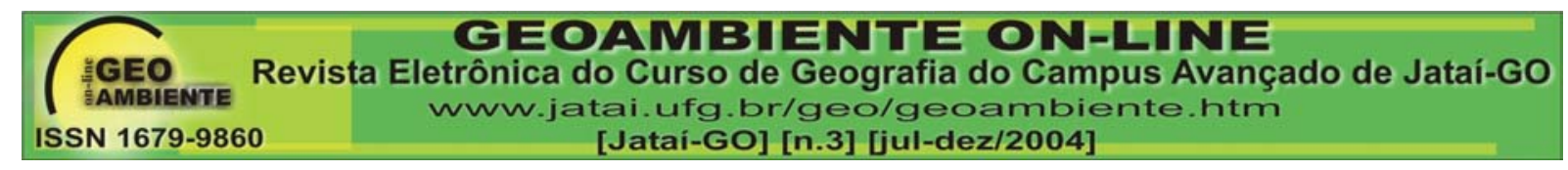

estudo das atividades não agrícolas no meio rural, a questão do desenvolvimento, porém, não se restringe à possibilidade de sua expansão.

Existe, na área estudada, a necessidade da construção de um sujeito coletivo do desenvolvimento que vai exprimir a capacidade de articulação entre as forças dinâmicas da região. Esta constatação é verificada por meio da análise das respostas dos representantes do poder público, no momento da entrevista. O que se verifica é uma visão fragmentada sobre o que se pode fazer para o desenvolvimento da região. Cada governo pensa em suma no que é importante momentaneamente para o "seu" município, o que demonstra uma dificuldade em se pensar coletivamente e até mesmo de um pensamento único para desenvolver economicamente a região como um todo com base, principalmente, nos preceitos de sustentabilidade.

Por meio da análise dos aspectos econômicos e do histórico da região pôde-se verificar algumas características regionais que são peculiares também a outras regiões do Estado de São Paulo e do país.

Em primeiro lugar o grau de relativo atraso na integração e diversificação de sua base produtiva, principalmente quanto às atividades agropecuárias, gerou uma estrutura pouco acentuada de divisão do trabalho, um fraco processo de relações mercantis e uma fraca dinâmica econômica intersetorial e inter-regional.

Em segundo lugar, uma baixa condição de estruturação do espaço, com uma rede urbana bastante rarefeita por cidades de pequeno porte e por pouca ligação entre elas, o que torna seu espaço descontínuo e confere-lhe uma característica desestruturante.

Em contrapartida, os aspectos naturais da região se apresentam como alternativa para o desenvolvimento por ter um valor ambiental e turístico expressivo. A paisagem cênica da região, principalmente em Analândia e Itirapina é o que move parte da economia dos municípios.

Com isso, pode-se considerar que um plano de ação para a Bacia Hidrográfica do Rio Corumbataí pode obedecer algumas características em comum para todos os municípios visando o desenvolvimento da região.

No que tange a agricultura deve-se desenvolver atividades agrícolas ligadas aos pequenos produtores: hortifrutigranjeiros (com adubos orgânicos); produtos artesanais (cachaças, licores), floricultura (principalmente as exóticas, como as orquídeas), além de cogumelos, maracujá, entre outros. Devem-se também criar vínculos entre os pequenos proprietários de terras e as agroindústrias. 


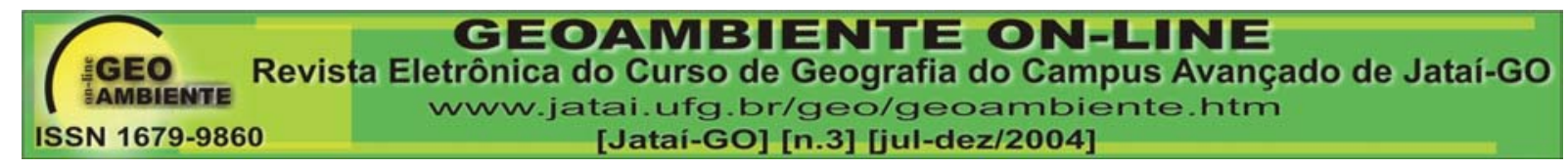

No segmento industrial verifica-se a importância do crescimento dos setores alimentícios, de confecções, químico e de extração mineral, favorecendo a coesão espacial e o desenvolvimento dessas atividades. Os municípios de Santa Gertrudes e Rio Claro têm um potencial centrado na indústria de transformação, mais especificamente nas cerâmicas.

No setor industrial, considerando a possibilidade de crescimento de pequenas e médias empresas, há a necessidade do aumento de capacidade das incubadoras de empresas.

No setor de comércio e serviços verifica-se um potencial elevado para o fortalecimento das atividades nos ramos de cerâmica e turismo.

Condizente com isso, faz-se necessário à ampliação do poder regional de atração do comércio, principalmente nas cidades menores.

O desenvolvimento de todas as atividades ligadas ao turismo contribui para o crescimento da região. A participação da comunidade local e a criação de Comissões Municipais e Regionais de Turismo são o grande desafio para o desenvolvimento turístico na região. Paisagens atraentes já existem, há a necessidade da criação de políticas de desenvolvimento turístico regional.

Contudo, a natureza da organização de um plano de desenvolvimento econômico não se decreta. Resulta de processos de aprendizagem que evoluem com o tempo.

Os objetivos de uma política de desenvolvimento pensados para determinada região seriam o de atribuir ao tecido econômico regional propriedades para um desenvolvimento autônomo. Entretanto, para ser eficaz, a política deve ser conduzida por parcerias com os atores do setor público, privado e comunidade em geral em busca da elevação do estado de bem-estar humano e ambiental.

\section{Referências Bibliograficas}

ABLAS, L. A. de Q. A questão regional: a diversidade na homogeneidade. In: LAVINAS, L. (org.). Reestruturação do Espaço Urbano e Regional no Brasil. ANPUR. HUCITEC, 1995.

AIYAR, S. S.; PIRIOU-SALL, S.; MCLEAN, K.; WILLIAMS, M. The political economy of democratic decentralization. Washington, DC: World Bank-Agricultural \& Natural Resources Department, 1996. 4p.

ALMEIDA, J. R. de (coord.). Planejamento Ambiental. Caminho para participação popular e gestão ambiental para o nosso futuro comum. Uma necessidade, um desafio. Rio de Janeiro: Thex Editora, 1993. 176p. 
ALMEIDA, M. H. T. de. Federalismo e politicas sociais. In: AFFONSO, R.; BARROS

SILVA, P. L., org. Federalismo no Brasil: descentralização e políticas sociais. São Paulo: FUNDAP, 1996.

BORBA, M. M. Z. Adequação da força de trabalho rural na moderna agricultura da região de Ribeirão Preto. Campinas: Universidade de Campinas, 2001. Tese de Doutorado.

CAMPANHOLA, C.; GRAZIANO DA SILVA, J. Diretrizes de políticas públicas para o novo rural brasileiro: incorporando a noção de desenvolvimento local. In: CONGRESSO BRASILEIRO DE ECONOMIA E SOCIOLOGIA RURAL, 37., 2001, Foz do Iguaçu. Anais... Foz do Iguaçu: SOBER, 2001. p.47-57.

CENTRO DE ANÁliSE E PLANEJAMENTO AMBIENTAL. Atlas Ambiental da Bacia do $\begin{array}{llllll}\text { Corumbatai } & - & \text { SP. } & \text { Disponível } & \text { no }\end{array}$ $<$ http://www.rc.unesp.br/igce/ceapla/atlas/index.html>. Acesso em fevereiro de 2004.

GARCIA, G. J. Planejamento e Gestão Integrada de Recursos em Bacias Hidrográficas. In: LOMBARDO, M. A. (coord.). Geografia da Paisagem: Um desafio a Interdisciplinaridade. São Paulo: Editora Unesp, 2004.

GRAZIANO DA SILVA, J. A globalização da agricultura. In: SILVEIRA, M.A. da; VILELA, S.L. de O., ed. Globalização e sustentabilidade da agricultura. Jaguariúna: Embrapa Meio Ambiente, 1998. p.29-42.

GRAZIANO DA SILVA, J. O novo rural brasileiro. Campinas: UNICAMP, Instituto de Economia, 1998. 153p. (Coleção Pesquisa, 1).

KOFFLER, N. F. O uso das terras da Bacia do Rio Corumbataí em 1990. In: Geografia, Rio Claro, 18 (1): 135-150, abril 1993.

NOGUEIRA, E. A. Desenvolvimento Regional, Ocupação do Espaço Rural e o Mercado de Trabalho no Sudoeste do Estado de São Paulo. São Paulo: Universidade de São Paulo Departamento de Geografia - Faculdade de Filosofia, Letras e Ciências Humanas, 1999. Tese de Doutorado.

RODRIGUES, A. B. (org.). Turismo e desenvolvimento local. São Paulo: Hucitec, 1997.

ROMEIRO, A. D.; REYDON, B.P.; LEONARDI, M. L.A., org. Economia do meio ambiente: teorias, políticas e a gestão de espaços regionais. Campinas: Unicamp, 2001.

SACHS, I. Gestão Negociada e Contratual da Biodiversidade. Brasília: mímeo, 2000. 


\section{IGEO CEOAMBIENTE ON-LINE}

SARACENO, E. Urban-rural linkages, internal diversification and external integration: a European experience. Políticas Agrícolas, n. especial, p. 71-104, 1998.

SCHNEIDER, S. As atividades rurais não agrícolas e as transformações no espaço rural: perspectivas.recentes.http://www.eco.unicamp.br/projetos/rurbano/textos/downlo/cad_est udos.html. Último acesso em 04 de fevereiro de 2004. 